\title{
A New Species of Belaphopsocus Badonnel (Psocodea: 'Psocoptera': Troctomorpha: Liposcelididae: Embidopsocinae) from Costa Rican Amber ${ }^{1}$
}

\author{
Edward L. Mockford ${ }^{2}$
}

\begin{abstract}
Belaphopsocus groehni, new species, is described from a single specimen in amber found on the Pacific coast of the Nicoya Peninsula, Costa Rica. This macropterous female is compared to other known macropterous females of the genus, as well as to apterous forms, and a key to the known species is included.
\end{abstract}

Key Words: 'Psocoptera', Liposcelididae, Belaphopsocus, new species, Costa Rican amber

\section{Introduction}

In his monograph of the psocids of Angola, Badonnel (1955) described the genus Belaphopsocus, based on a single apterous female. The opening sentence of his description expressed uncertainty as to the family placement of this genus, noting that certain characters suggested affinity with the family Pachytroctidae, whereas certain others suggested proximity to the family Liposcelididae. He chose the latter family, where this genus has remained. Subsequently, New (1971) described Belaphopsocus badonneli from central Brazil, including description of the macropterous female, which clearly confirmed the family placement of both species in Liposcelididae. Lienhard (1991) described Belaphopsocus murphyi from Singapore with comparative notes on the three species. Grimaldi and Engel (2006) described Belaphopsocus dominicus from the Dominican Republic amber, but did not include comparisons with the other known species of the genus.

This paper describes a new species based on a single macropterous female in amber from Costa Rica. The specimen is thought by its collector to be early Miocene in age (ca. 20-25 mybp, C. Gröhn, in litt.). It agrees with B. badonneli in general fore wing venational features, but the veins are very distinct, slightly different in orientation, and other differences are noted in the diagnosis. Differences from $B$. dominicus are also noted in the diagnosis.

A swelling along vein R1 in the fore wing of the new species, as well as a thickening of this vein seen in figures of the other two species known from

\footnotetext{
${ }^{1}$ Submitted on August 10, 2015. Accepted on August 13, 2015. Last revisions received on September 22, 2015.

${ }^{2}$ School of Biological Sciences, Illinois State University, Normal, Illinois 61790-4120 USA. Email: elmockf@ilstu.edu
} 
macropterous females, suggests the remnant of a stigmapophysis (= nodus). This would be the only remnant of the structure known in the family Liposcelididae.

\section{Methods}

The single fossil specimen is in a piece of amber $16 \times 10 \times 6 \mathrm{~mm}$ of rather complex structure. One plane passes through the specimen such that anterior features are visible on one side of the plane and posterior features on the other. A clear dorsal or clear ventral view could not be had and all observations had to be made on the lateral, dorso-lateral, and ventro-lateral views. Most observations were made with a Wild (Heerbrugg) dissecting microscope at 25-150X. A few observations (notably, lacinial tip, antennal tip, and region of vein R1 of forewing) were made with a Leitz Dialux compound microscope at 160X. Measurements, expressed in $\mu \mathrm{m}$, were made with a filar micrometer mounted on the Wild microscope. The photograph was taken with a ProgRes ${ }^{\mathrm{TM}} \mathrm{C} 10$ camera mounted on the Wild microscope.

Most line drawings had to be made free-hand as a drawing tube rendered figures too small for use, but the fore wing, hind wing, and front tibia plus tarsus figures are based on figures made with a drawing tube and subsequently magnified on a copy machine.

Abbreviations used in the descriptions and measurements are explained as follows: $\mathrm{BL}=$ body length (in this case made in two sections separated by a plane in the amber, hence the approximation); $\mathrm{F}=$ length of hind femur; f1...f7 $=$ antennal flagellomeres $1-7 ; \mathrm{FW}=$ fore wing length; $\mathrm{HW}=$ length of hind wing; P4 = terminal segment of maxillary palpus (length not recorded); $\mathrm{T}=$ length of hind tibia; $\mathrm{t} 1, \mathrm{t} 2$ = hind first and second tarsomeres and their lengths; $\mathrm{V}$ $=$ greatest width of vertex taken immediately above compound eyes (an approximation, as the head could not be placed in the precise position for the measurement). Deposition of the type will be as noted in the description.

\section{Systematic Entomology \\ Belaphopsocus groehni new species}

Figures $1-10$

Diagnosis. With the characters of the genus: P4 swollen; antennae short, with 7 flagellomeres; tarsi 2-segmented; in the fore wing, veins reduced to faint indication of $\mathrm{Sc}$ near wing base, $\mathrm{R}$ once-branched, $\mathrm{M}+\mathrm{Cu}$ simple, A simple. Differing from $B$. badonneli by having slenderer fore wings with very distinct veins, vein $\mathrm{M}+\mathrm{Cu}$ slightly curved posteriorly in its distal one-third, vein A much longer, and the hind wing not broadening in its distal three-fourths. Differing from $B$. dominicus by having a much rounder head with less protrusive compound eyes and postclypeus, a broader P4, and lacinial tip bifid (Figure 4). Macropterous forms of other extant species not known. 

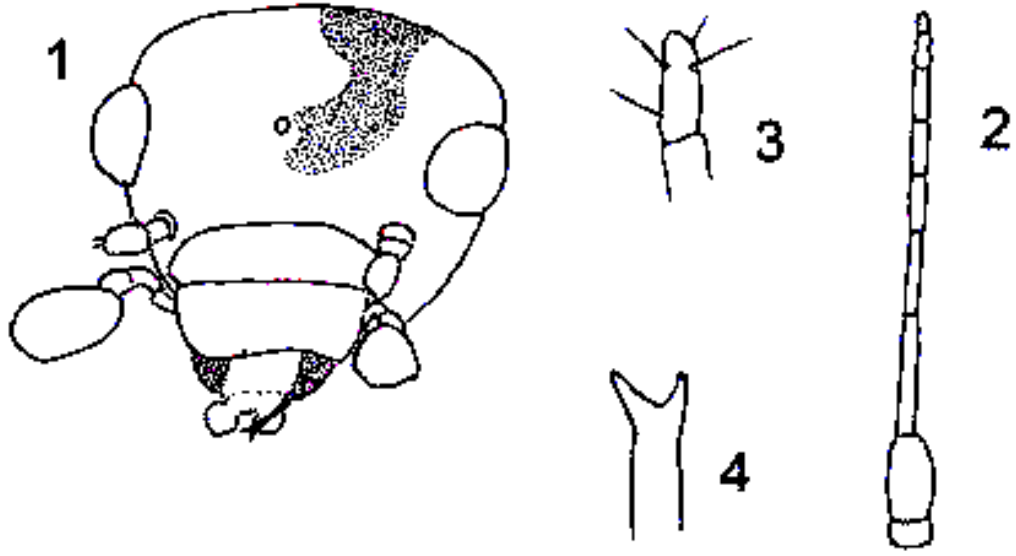

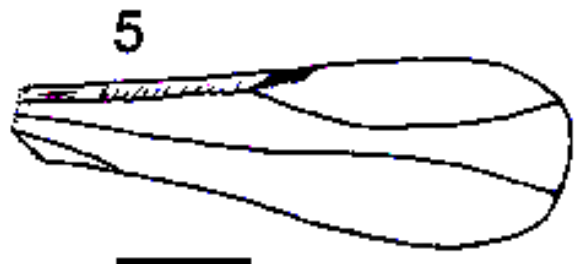

0.33

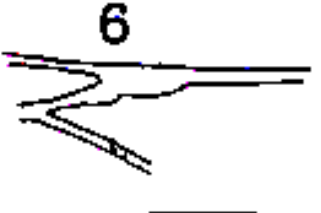

0.1
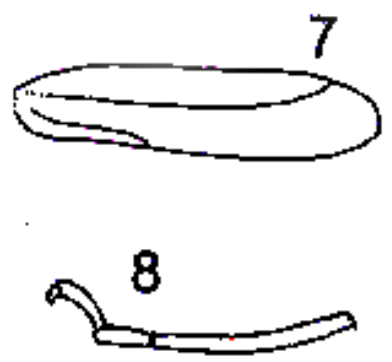

0.33

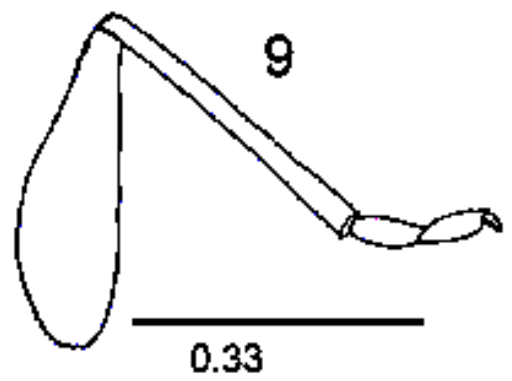

Figures 1 - 9. Belaphopsocus groehni new species, macropterous female. 1. Head, near front view, slightly skewed rightward. 2. Antenna reconstructed from near-dorsal and near-lateral views. 3. Terminal antennal segment (f7) and tip of f6 reconstructed from observation at 160X. 4. Lacinial tip drawn from observation at 160X. 5. Fore wing (drawing tube figure). 6. Region of R1-Rs branching (drawing tube figure). 7. Hind wing, drawing tube Figure. 8. Front tibia, tarsus, and pretarsus (drawing tube figure). 9. Hind femur, tibia, tarsus, and pretarsus, drawing tube figure. 
Color. [Note. A large, dark spot in the middle of the vertex, probably resulting from injury, obscures the anterior and left ocelli]. Body and legs medium brown; antennae paler brown. Wing membranes tawny-washed, unmarked; veins brown.

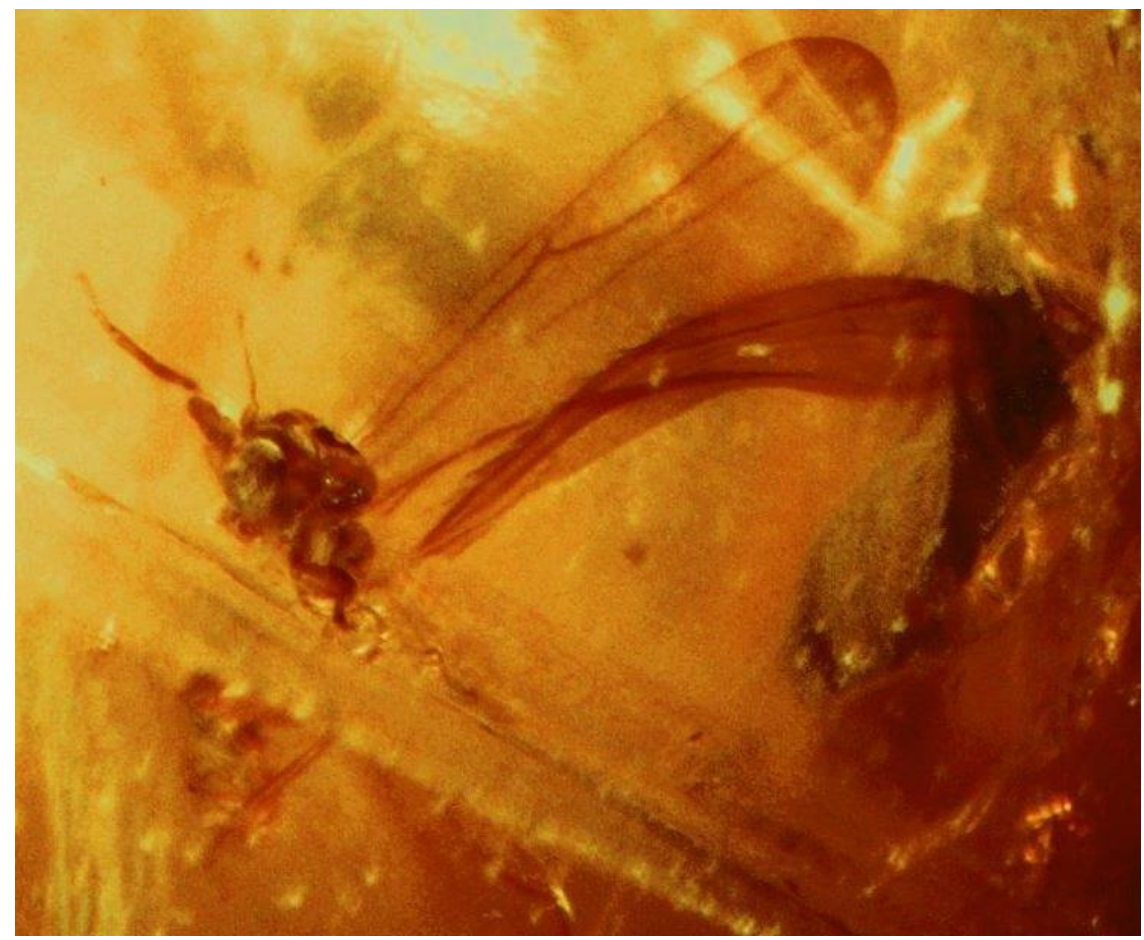

Figure 10. Belaphopsocus groehni new species. Near-frontal image of whole specimen.

Structural Characters. Head rounded, not with triangular aspect (Figure 1). Compound eyes well separated from hind margin of vertex, many faceted (estimated 45-50). Ocelli present, right lateral visible, ringed in black. Vertex with a few short, stout setae, none on the hind margin. P4 swollen, its length/greatest width $\approx 1.30$. Lacinial tip (Figure 4 ) bidentate, with large, pointed outer tooth and smaller, pointed inner tooth. Antennae (Figures 2, 3) about equal in length to width of head behind compound eyes, pedicel large, bulging, flagellum 7-segmented; f1 slightly longer than f2; f3-f5 about equal in length, each shorter than $\mathrm{f} 2$; $\mathrm{f} 6$ and $\mathrm{f} 7$ each shorter than preceding segments, f6 slightly constricted in middle, f7 (Figure 3) rounded at tip, bearing 4 long setae, 3 of them subapical. Tibiae of front legs slightly curved (Figure 8). Hind leg (Figure 9, femur through pretarsus): femur broad basally, narrowing distally, tibia only slightly longer than femur; t1 and t2 (of all legs) about equal in length; 
detailed structure of pretarsal claws not observed, but their shape suggestive of that noted by Lienhard (1991). Fore wing (Figure 5) gradually broadening from relatively slender base to greatest width at about distal three-fourths with a distinct anal angle; a distal clouded area on vein R1 suggestive of remnant of stigmapophysis (Figure 6); vein Rs bowed, terminating on wing margin anterior to apex; vein $\mathrm{M}+\mathrm{Cu}$ straight to about distal three-fourths length of wing, then curving slightly to wing margin posterior to apex; vein A short, reaching wing margin distal to anal angle. Ciliation of fore wing consisting of a row of short setae on vein $R$ before its branching. Hind wing (Figure 7) varying little in width throughout its length, with a single vein $\mathrm{R}$ running straight most of its length and curving forward near its distal end to meet margin before wing apex; vein A parallel to hind margin of wing, curving to meet wing margin at about one-third length of wing. Abdomen flat, its features not discernible.

Measurements $(\mu \mathrm{m}) . \mathrm{BL}=1108 ; \mathrm{FW}=1490 ; \mathrm{HW}=1079 ; \mathrm{V} \approx 279 ; \mathrm{F}=$ 345; $\mathrm{T}=375 ; \mathrm{t} 1=77 ; \mathrm{t} 2=82$.

Type Locality: Costa Rica: Puntarenas Province: Nicoya Peninsula: Mal Pais on Pacific coast. The amber was embedded in very hard sandstone in the intertidal zone. It is thought to be about $20-25$ million years old (C. Gröhn, in litt.). The type will be deposited in the Geology-Palaeontology Institute (GPIH), Hamburg, Germany.

Etymology. The species in named for its collector, Mr. Carsten Gröhn, who is affiliated with the Museum of the Geology-Palaeontology Institute, University of Hamburg, Germany.

\section{Discussion}

Lienhard (1991) has noted that several characters of Belaphopsocus are "manifestations of neoteny," including reduction of antennal flagellomeres to 7 and reduction of tarsomeres to two. He also noted clearly apomorphic characters of the structure of P2 and the pretarsal claws. Yoshizawa \& Lienhard (2010) provide a morphologically based phylogeny of the family Liposcelididae in which Belaphopsocus and its apparently close relative Troctulus Badonnel occupy a rather highly derived position. Nevertheless, several morphological aspects of Belaphopsocus appear to be plesiomorphies at the family level. These include the rounded, unflattened general body shape, and the correlated relatively slender thoracic sternites (Badonnel 1955, New 1971, Lienhard 1991). The widened R1 in the fore wing, which in B. groehni appears somewhat roughrounded on its distal surface (Figure 6) suggests a remnant of the stigmapophysis. The subtle curve of the vein Rs in the fore wing, tending slightly forward in its distal half, is seen again in the family only in Cretoscelis burmitica Grimaldi and Engel (see Grimaldi and Engel, 2006, Figures 1a, c). It suggests the path Rs might have taken in some unknown ancestral form in which it would branch distally. 


\section{Acknowledgements}

I thank Mr. Carsten Gröhn for the loan of the specimen studied here. I also thank Anne Eggert and Charles Lienhard for critical reading and useful comments prior to submission of the manuscript, and G. Ower for technical support.

\section{Literature Cited}

Badonnel, A. 1955. Psocoptères de l'Angola. Publicacões culturais da Companhia de Diamantes de Angola 26:1-267, 625 figs.

Grimaldi, D. and M. S. Engel. 2006. Fossil Liposcelididae and the lice ages. Proceedings of the Royal Society of London, Series B, Biological Sciences 273:625-633. http://dx.doi.org/10.1098/rspb.2005.3337

Lienhard, C. 1991. New records and species of Belaphopsocus (Psocoptera: Liposcelididae). Raffles Bulletin of Zoology 39(1):75-85.

New, T. R. 1971. A new species of Belaphapsocus [sic] Badonnel from Brazil with notes on its early stages and bionomics (Psocoptera). Entomologist 104:124-133.

Yoshizawa, K. and C. Lienhard. 2010. In search of the sister group of the true lice: a systematic review of booklice and their relatives with an updated checklist of Liposcelididae (Insecta: Psocodea). Arthropod Systematics \& Phylogeny 68(2):181195.

$\not a \not a$

\section{Erratum}

\section{Norman Greenhawk}

Tropic Ventures and Educational Research Foundation, Las Casas de La Selva HC-63, Buzón 3879, Patillas, Puerto Rico 00723

Recently, I (Greenhawk 2014) published a paper entitled, "On the Consumption of marshmallow residues, an atypical food item, by Anolis cristatellus Duméril and Bibron, 1837 in Puerto Rico", published in Life: The Excitement of Biology 2(4):270-271. There, I stated, "I believe this is the first record of an anole consuming a humanmanufactured food item." Although this paper was reviewed by three knowledgeable Caribbean herpetologists, the quoted statement is untrue. Through the blog Anole Annals, I became aware that anoles consumed jellied candies that were offered to them (Rand, A. S., G. Gorman, and W. Rand. 1975. Natural history, behavior, and ecology of Anolis agassizi. pp 27-38. In, The Biological Investigation of Malpelo Island, Colombia J. B. Graham (Editor). Smithsonian Contributions to Zoology. Volume 176. 98 pp. http://www.sil.si.edu/smithsoniancontributions/zoology/pdf_hi/SCTZ-0176.pdf . Specifically, "chuckles", brightly colored "jelly candies coated with a light layer of sugar" apparently popular then, were offered to Anolis agassizi Stejneger, 1900, in an experiment conducted on Malpelo Island (Colombia). Although they showed that the lizards preferred yellow and orange chuckles over red, green and black, the anoles consumed all they were offered. 